\title{
A TECNOLOGIA CARBOVAL DE PRODUÇÃO INTEGRADA DO CARVÃO VEGETAL SIDERÚRGICO*
}

Fabiano Mendes ${ }^{1}$ Fernando Lopes Latorre ${ }^{2}$ Lis Soares ${ }^{3}$

Flavio Azevedo 4 Ronaldo Sampaio 5

\section{Resumo}

Processos industriais de carbonização são tecnologias maduras e operam há mais de 7 décadas. Contudo, o sistema integrado de produção de ferro primário e aços a base de biomassa como fonte de energia e termorredutor, mesmo sendo a alternativa ambiental de menor impacto existente, chega a seus limites tecnológicos, ambiental e econômico, ameaçando a sua sustentabilidade. O grupo Vallourec buscou o processo Lambiotte como base tecnológica para desenvolver seu ambicioso projeto de carbonização contínua, em substituição ao processo artesanal de fornos retangulares de batelada, utilizados atualmente. O esforço experimental de mais de meia década, com a adaptação e profunda reengenharia do processo Lambiotte, que é o que melhor representa esta classe de reatores, para que ele atendesse as condições brasileiras e o uso das espécies de madeira da família dos Eucaliptos culminou no desenvolvimento do processo de carbonização continua Carboval, que demonstrou sua plena capacidade, para atender aspectos econômicos, sustentáveis e de qualidade siderúrgica do carvão vegetal produzido.

Palavras-chave: Carbonização contínua; Processo lambiotte; Carvão vegetal.

\section{THE CARBOVAL TECHNOLOGY OF INTEGRATED CHARCOAL PRODUCTION FOR IRONMAKINNG}

\section{Abstract}

Industrial processes to produce charcoal are mature technology and exist for more than 7 decades. However, the integrated system of primary iron production and biomass-based steel as a source of energy and thermal-reducer, even though the alternative of smaller existing impact, reaches its technological, environmental and economic limits, threatening their sustainability. The Vallourec group chosen Lambiotte process as a technological basis for developing its ambitious continuous carbonization project, replacing the batch process in rectangular masonry kilns currently used. The experimental efforts of more than half decade, with adaptation and deep reengineering of the Lambiotte process, which is what best represents this class of reactors, so that it would meet the Brazilian conditions and the use of Eucalyptus wood species culminated in development of continuous carbonization process Carboval, which demonstrated its full capacity to meet economic, sustainable and steel quality of charcoal.

Keywords: Continuous carbonization; Lambiotte process; Charcoal.

Engenheiro Metalúrgico, Engenheiro, VFL, Curvelo, MG, Brasil.

Engenheiro Metalúrgico, Gerente Projeto Carboval, VFL, Curvelo, MG, Brasil.

Engenheira Mecânica, Dra., Engenheira Especialista Sênior, Vallourec Tubos do Brasil S.A

Engenheiro Metalúrgico,M.Sc., Dr.Ing., Vice-President Tecnologia e Inovação, Vallourec, França.

Engenheiro Metalúrgico,M.Sc., Ph.D, Consultor, RSConsultants Ltda. 


\section{INTRODUÇÃO}

O sistema integrado de produção de ferro primário e aços a base de biomassa como fonte de energia e termorredutor, presente no Brasil, mesmo sendo a alternativa ambiental de menor impacto existente e possível de existir para a produção industrial de um metal a partir de minérios (SAMPAIO, 2011), chega a seus limites tecnológicos, ambiental e econômico, ameaçando a sua sustentabilidade.

Ao persistirem, ainda neste século, os processos artesanais de produção de Carvão Vegetal, CV, com base em fornos de tijolos, manteve-se a dependência do controle de processo nas habilidades de verdadeiro artesão do carvoeiro, como o maior responsável pela garantia da qualidade do processo e do produto, atuando por meio de limitado controle da combustão parcial da madeira e convecção natural dos gases combustos quentes em seu interior.

As inúmeras melhorias que aconteceram nestes fornos, nos últimos anos, sempre estiveram relacionadas ao aumento da produtividade, pelo aumento do tamanho dos fornos, da maior mecanização das operações de corte de madeira, do manuseio e secagem natural no campo e do transporte das lenhas para serem, mecanicamente enfornadas. Também aconteceram esforços de uso de sensores de temperatura para auxílio aos operadores, no controle do ritmo das etapas da carbonização onde a temperatura interna é um dos parâmetros de maior importância para o sucesso de uma boa conversão da madeira a Carvão Vegetal siderúrgico.

O carvão vegetal, ao ser retirado dos fornos de forma mecanizada, através de pás carregadeiras, passa pela operação de separação das frações não carbonizadas (tiço) e sofre, nestes manuseios a contaminação com resíduos do solo, terra. Como resultado destas operações de manuseio e empilhamentos, elevou-se também a geração de frações finas, não possíveis de serem carregadas pelo topo nos altos fornos. Estes aspectos implicam em teores de cinzas superiores a 4\%, resultando em maior consumo de CV de floresta por unidade de gusa produzida.

Focada na necessidade de aprimoramento tecnológico do processo de carbonização, para garantir a sustentabilidade deste modelo siderúrgico ambientalmente favorável, o grupo Vallourec iniciou em 2008 o investimento para desenvolver uma planta de carbonização contínua (Carboval) baseada na consagrada tecnologia Lambiotte (FAO, 1985), a partir de uma planta já existente na França com mais de 50 anos em operação industrial.

Ao longo dos últimos 8 anos foram efetuados diversos desenvolvimentos em alternativas tecnológicas para atingir-se o melhor desempenho do reator Carboval e do sistema integrado de produção de CV siderúrgico, da "árvore-em-pé" ao CV limpo, homogêneo e em grãos, entregue nos altos-fornos de acordo com suas especificações mais restritas. Foram aprimorados o processo de fracionamento da madeira em toretes, o manuseio e secagem dos toretes para a sua alimentação no reator Carboval e os sistemas de geração de gás quente e controle de carbonização do reator, envolvendo a etapa de resfriamento e inertização do CV produzido. Este desenvolvimento tecnológico abrangente consolidou a Tecnologia Carboval de Produção Integrada do Carvão Vegetal Siderúrgico.

O período de operação desta planta em escala industrial permitiu o domínio do processo focado na produção de CV metalúrgico, livre de contaminações, com a sua química homogênea e perfeitamente adequada a seu uso em AF, situação impossível nos processos artesanais de fornos de alvenaria.

O desenvolvimento da tecnologia tornou este sistema rentável do ponto de vista econômico. Além disso, dois pontos reforçam a competitividade deste sistema: 1: 0 
aproveitamento dos resíduos florestais e do material volátil da madeira para termogeração traz a possibilidade de redução expressiva dos custos produtivos através de crédito com a venda de energia elétrica. 2: redução de consumo específico de carvão vegetal nos altos fornos, o que reduz os custos de produção ferro gusa, e é escopo de outro trabalho a ser apresentado neste Seminário.

O presente artigo apresenta a Tecnologia Carboval de Produção Integrada do Carvão Vegetal Siderúrgico e a quantificação de parâmetros de processos importantes para a validação da nova tecnologia durante o processo de produção.

\section{SISTEMA CARBOVAL DE PRODUÇÃO INTEGRADA DO CARVÃO VEGETAL SIDERÚRGICO}

A produção de CV através da Carbonização Contínua Carboval (Figura 1a, b e c), apresenta diferenças ao longo de praticamente todo o sistema em relação aos sistemas convencionais. Apenas parte da etapa do manejo florestal é comum a ambos os sistemas.

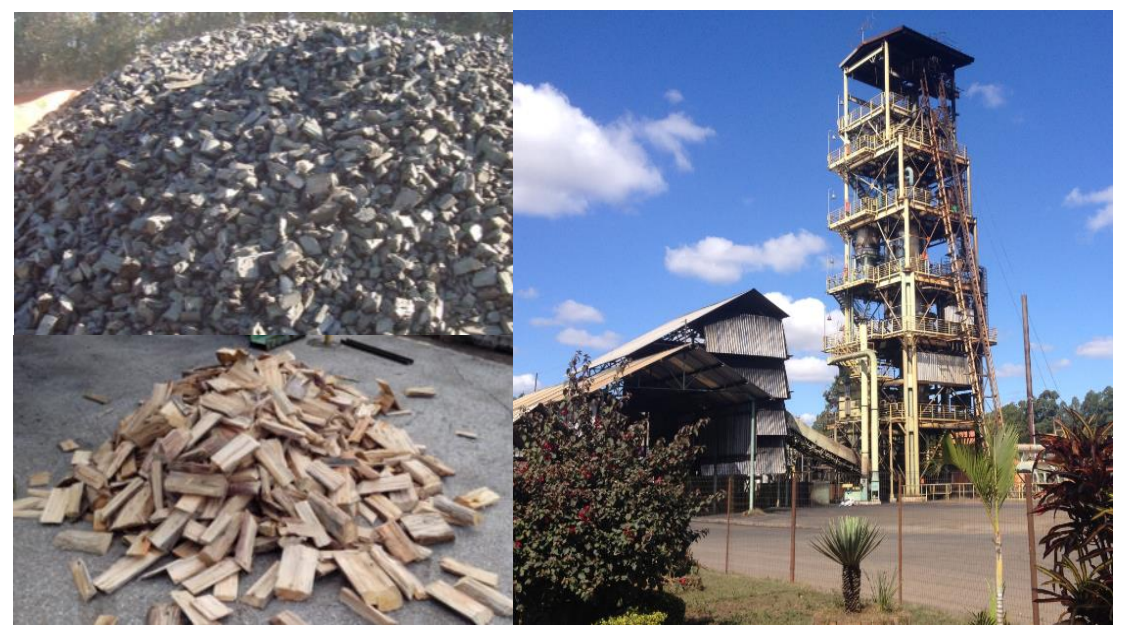

Figura 1a (canto superior esquerdo): Carvão produzido pelo Sistema Carboval. Figura 1b (canto inferior esquerdo): Madeira picada utilizada no processo Carboval. Figura 1c (à direita): o reator de carbonização contínua Carboval.

A Figura 2 ilustra esquematicamente o que constitui o Sistema Integrado Carboval de Produção de Carvão Vegetal Siderúrgico e o similar atual com base nos fornos artesanais de alvenaria retangulares de grande porte. Logo na etapa de colheita, a madeira colhida é picada em toretes de $20 \mathrm{~cm}$ de comprimento, alimentadas em uma carreta do tipo piso móvel ou báscula, e levadas diretamente para o pátio pavimentado da planta industrial de carbonização contínua Carboval para estoque operacional.

Nesta típica unidade industrial têm-se três outras operações que acontecem em sequência: 1- a secagem dos toletes a níveis de umidade da ordem de $30 \%$ em base seca; 2 - carbonização no forno com resfriamento primário na mesma, e 3 resfriamento secundário, em que é feita a passivação do carvão vegetal em silos externos que também armazenam o carvão vegetal para o carregamento por gravidade nos caminhões que o levam para a siderúrgica. 


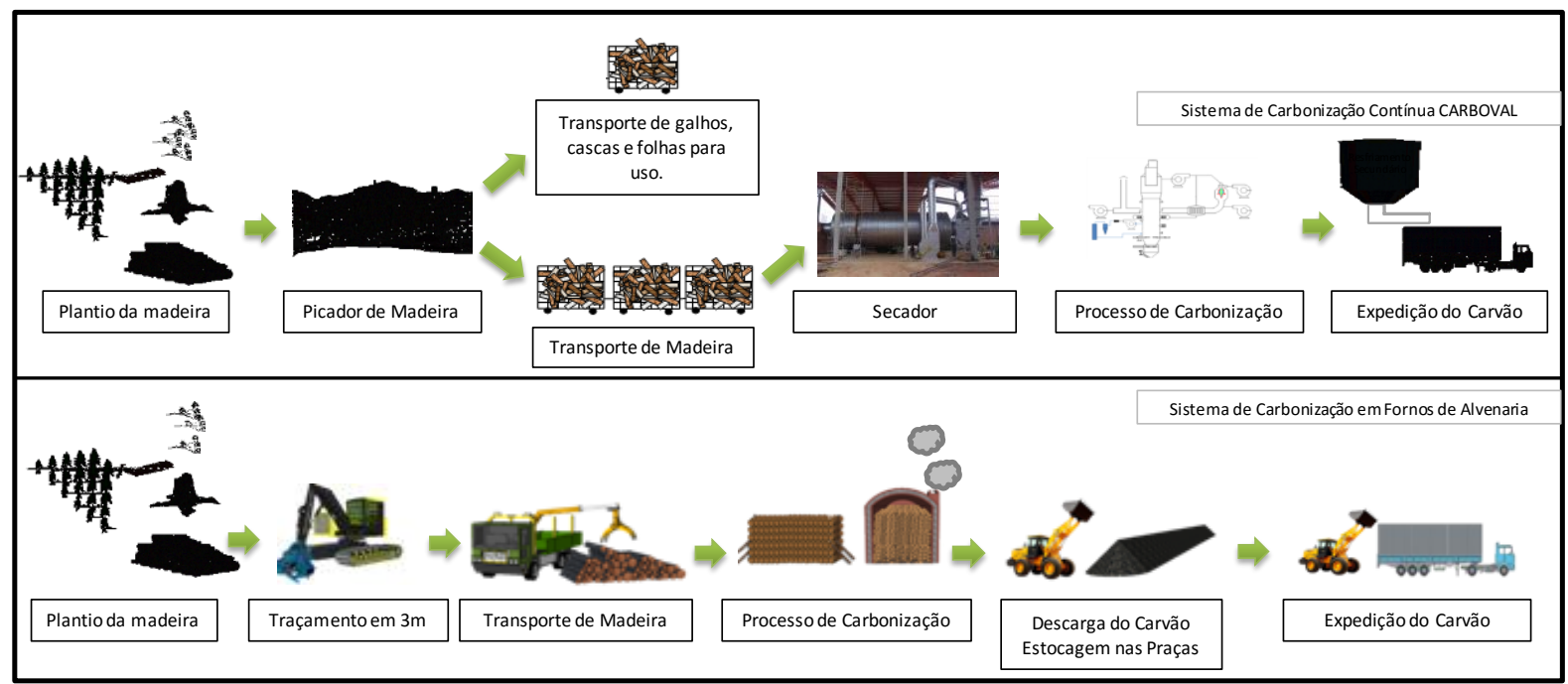

Figura 2 - Fluxo esquemático dos sistemas de produção de carvão contínuo Carboval e em Fornos de Alvenaria.

A Tabela 1 resume as principais diferenças em etapas e equipamentos utilizados e 0 tempo envolvido no Sistema Carboval versus os equivalentes nos processos artesanais de alvenaria retangulares de grande porte.

Tabela 1 - Etapas de produção do carvão vegetal siderúrgico: Da floresta ao carvão vegetal entregue no topo dos altos fornos.

\begin{tabular}{|c|c|c|}
\hline & Sistema Carboval de Carbonização Contínua & Fornos de Avenaria \\
\hline Floresta em pé & Não há restrição quanto a diâmetro da floresta. & Diâmetro acima de 20 cm não são adequados. \\
\hline Colheita & Feller Buncher / Skidder & Feller Buncher / Skidder \\
\hline $\begin{array}{l}\text { Partição das lenhas } \\
\text { (traçamento) }\end{array}$ & Picagem em toretes de $20 \mathrm{~cm}, 140 \mathrm{~m}^{3} / \mathrm{hora}$. & Garra traçadora em tamanhos de $3 \mathrm{~m}, 100 \mathrm{~m}^{3} /$ hora. \\
\hline $\begin{array}{l}\text { Redução da Umidade da } \\
\text { Madeira }\end{array}$ & Secador artificial. & Secagem natural no campo. \\
\hline $\begin{array}{l}\text { Tempo de estoque de } \\
\text { madeira }\end{array}$ & No máximo 30 dias. & $\begin{array}{l}\text { De } 120 \text { a } 200 \text { dias (função do diâmetro da floresta para } \\
\text { secagem natural). }\end{array}$ \\
\hline $\begin{array}{l}\text { Processo de carbonização e } \\
\text { resfriamento primário }\end{array}$ & $\begin{array}{l}\text { Ciclo de } 40 \text { horas (10 horas de carbonização }+6 \text { horas de } \\
\text { resfriamento primário }+24 \text { horas de resfriamento secundário). } \\
\text { Produção de } \sim 1 \mathrm{t} \text { (hora.torre). }\end{array}$ & $\begin{array}{l}\text { Ciclo de } 15 \text { dias ( } 5 \text { dias de carbonização }+10 \text { dias de } \\
\text { resfriamento). Produção de } 45 \text { t por ciclo. }\end{array}$ \\
\hline $\begin{array}{l}\text { Descarga do carvão vegetal } \\
\text { e separacão do tico }\end{array}$ & Direto por correia para silo de resfriamento secundário. & Realizada com pás carregadeiras. \\
\hline $\begin{array}{l}\text { Estocagem do carvão } \\
\text { vegetal }\end{array}$ & $\begin{array}{l}\text { Em silo, que além de armazenar o carvão são utilizados como } \\
\text { resfriamento secundário (mínimo de } 24 \text { horas). A estocagem em } \\
\text { silos implica na não contaminacão do carvão. }\end{array}$ & $\begin{array}{l}\text { Feita em praças de solo compactado. Tempo mínimo de } \\
\text { despacho de } 48 \text { horas. }\end{array}$ \\
\hline $\begin{array}{l}\text { Expedição do Carvão } \\
\text { Vegetal }\end{array}$ & Por gravidade dos silos para o caminhão. & $\begin{array}{l}\text { Feita com pás carregadeiras. Da praça de estocagem para o } \\
\text { caminhão. }\end{array}$ \\
\hline
\end{tabular}

A etapa de redução do tamanho da madeira (picagem) é realizada através de tecnologia consolidada na indústria de processamento de biomassa para uso em termoelétricas, que após diversas melhorias foi adaptada para um picador rotativo de peças grandes (acima $20 \mathrm{~cm}$ de comprimento). Este equipamento, além de ter uma produtividade maior que os processos convencionais, permite após a picagem, a separação das cascas, galhos e folhas, o que torna operacionalmente possível o aproveitamento desta fração, que chega a $25 \%$ da floresta, sendo os galhos e cascas em torno de $15 \%$ do peso (ALTHOFF 1999), e os outros $10 \%$ das cascas geradas na picagem dos toretes. Estes podem ser utilizados como fonte de energia para termoelétricas a biomassa.

A picagem é realizada em no máximo 30 dias após o corte da madeira e após esta, a madeira já está disponível para a próxima etapa. Este tempo de estoque de madeira, só é possível em virtude da existência de um secador de toretes, colocado ao lado do forno de carbonização. Este secador utiliza como fonte de energia para a secagem 
parte calor sensível contido nos gases gerados no processo de carbonização. Esta operação reduz o tempo de secagem da madeira, que, no sistema de carbonização artesanal varia de 120 a 200 dias (função do diâmetro da madeira úmida). O baixo estoque de madeira em secagem no campo reduz os custos do CV produzido.

No reator Carboval, o processo é automatizado, permitindo domínio e acompanhamento completo sobre as principais variáveis da carbonização, tais como vazão, temperatura dos gases recirculados e tempo de carbonização,tornando possível o ajuste do processo de forma a obter-se rendimento gravimétrico e os parâmetros de qualidade desejados para o CV siderúrgico. Além disso, o fato do perfil térmico do reator Carboval ser praticamente constante e com isotermas horizontais, implica numa grande homogeneidade das qualidades física e química do carvão vegetal, uma vez que todas as peças de madeira são submetidas às mesmas condições de tempo e temperatura dentro do forno. A Figura 3 mostra um exemplo do comportamento real de perfil térmico do forno, onde cada linha corresponde a um termopar em posição equivalente à torre ao lado do gráfico.

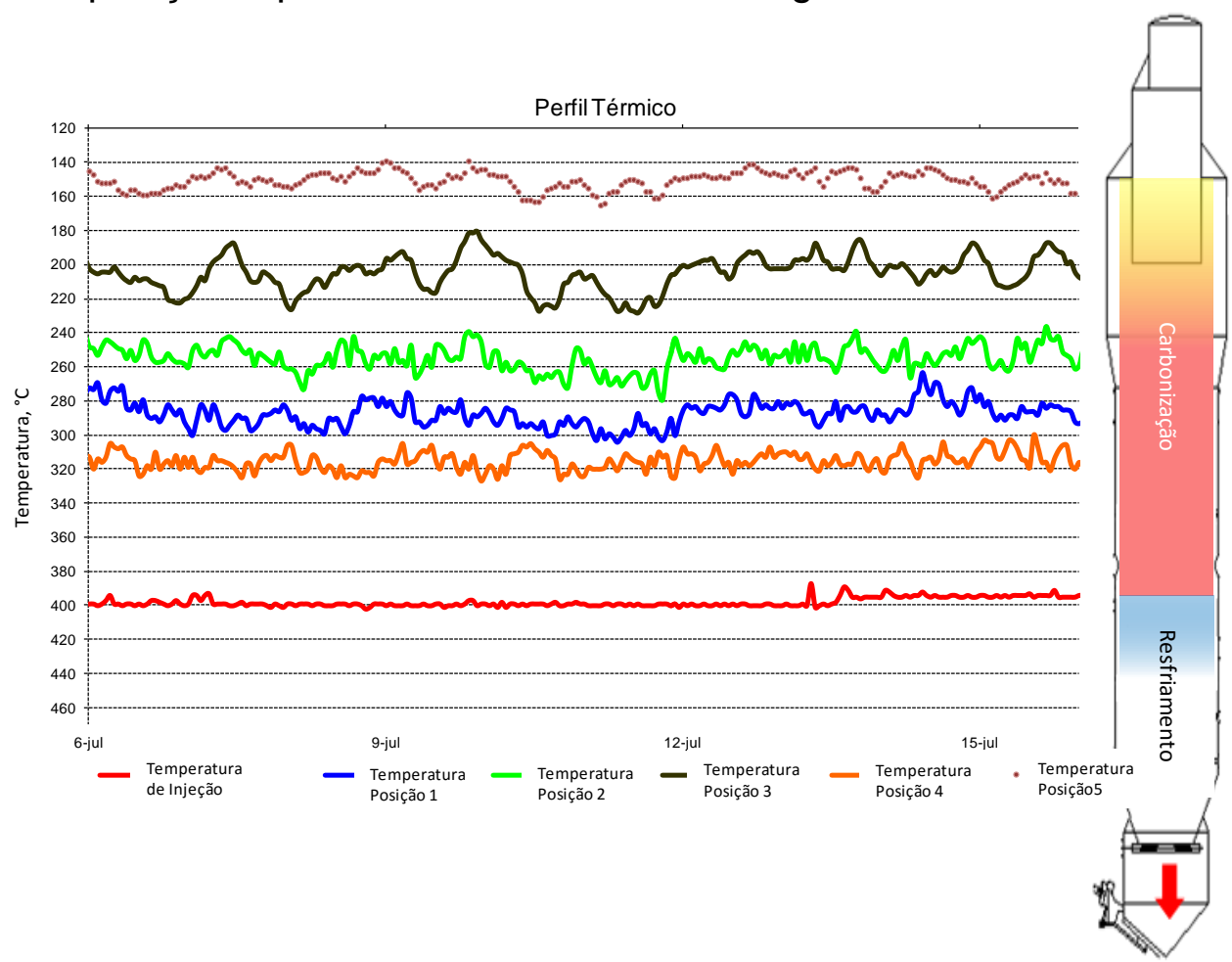

Figura 3 - Perfil Térmico do Forno de Carbonização Contínua (em escala invertida): As temperaturas crescem com a descida da madeira no sentido topo-base.

A carbonização é a degradação térmica da madeira em ambiente livre de oxigênio com o objetivo de concentração do carbono contido na madeira, assim, à medida que a temperatura de processo aumenta, maior será o teor de carbono fixo e menor será a massa residual (carvão vegetal) como mostra a Figura 4.b. Esta figura mostra o experimento realizado para determinação do efeito da temperatura e taxas de aquecimento no rendimento gravimétrico numa parceria entre a Universidade Federal de Lavras, CIRAD e Vallourec Florestal. 

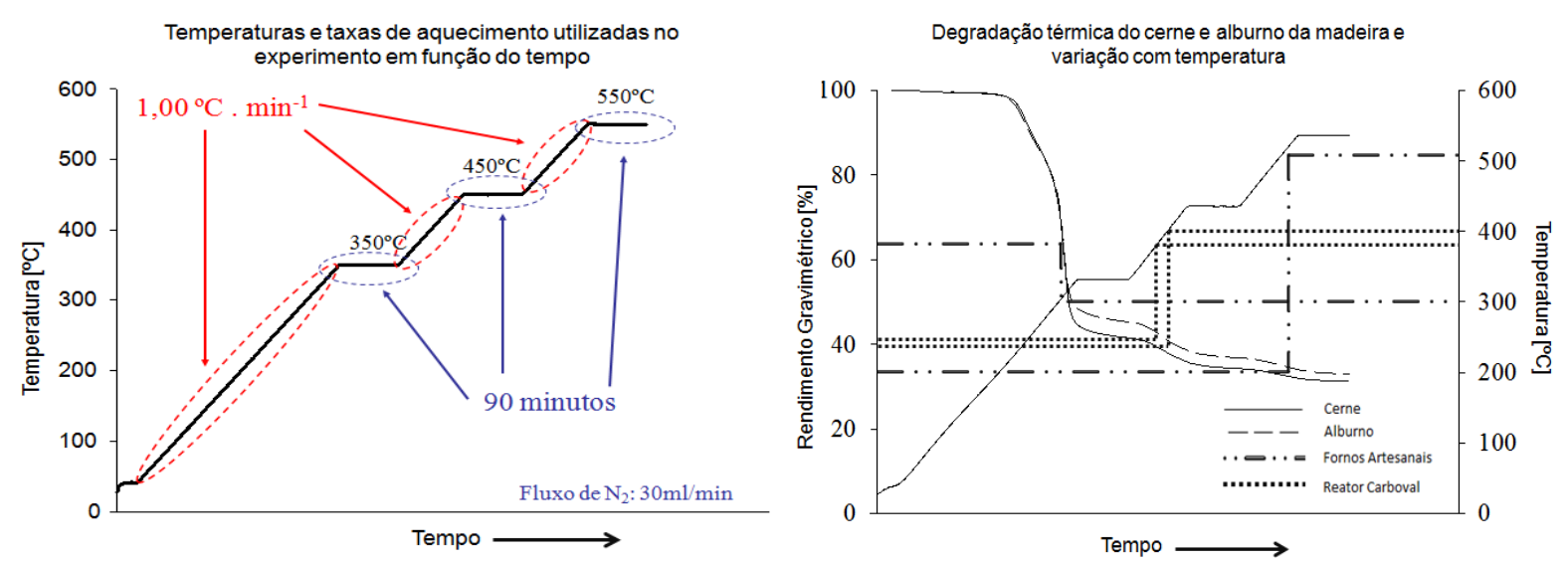

Figura 4.a: Temperaturas e taxas de aquecimento utilizadas no experimento.

Figura 4.b: Variação do Rendimento Gravimétrico com a temperatura.

Nos fornos artesanais de alvenaria há uma grande variação de temperaturas dentro do forno devido a este ser um reator primitivo, no qual a condução do processo é feita de forma artesanal sendo a principal força motriz a convecção natural dos gases no interior do forno, onde a frente de carbonização segue no sentido copa/piso do forno, o que implica em diferentes temperaturas e tempos de carbonização para as inúmeras posições no interior do forno. Essa elevada variação de temperaturas no interior do forno resulta na grande heterogeneidade química e física do carvão vegetal e de rendimento carvão/madeira.

No reator Carboval, a energia necessária para a degradação térmica da madeira é proveniente da recirculação dos gases provenientes da carbonização. Esse fato permite minimizar as perdas de energia durante o processo e consequentemente a obtenção de rendimentos gravimétricos muito próximos aos potenciais máximos possíveis como mostrado na Figura 4.

$$
R g=\text { Rend.Gravimétrico }=\frac{\text { Carvão Vegetal Seco Produzido }}{\text { Madeira Seca Enfornada }}
$$

Uma vez definido o carbono fixo e descontado a contaminação com terra, o rendimento gravimétrico (Equação 1) é a medida de conversão de madeira em carvão vegetal, assim, para uma mesma produção de CV, quão maior o rendimento gravimétrico do processo, menor será a área plantada necessária. É importante ressaltar que o conhecimento deste parâmetro com precisão é de suma importância para gestão do desempenho do processo. Assim, contaminantes, como terra e resíduos, e o tiço produzido, tem de ser retirados do numerador da Equação 1.

A qualidade química do CV utilizada pelo setor é a analise imediata, que mede dentro de norma ABNT 8112, as frações de material volátil, teor de cinzas e, por diferença o denominado carbono fixo. A fração de cinzas tem origem praticamente exógena, pela contaminação com o solo. As cinzas endógenas, que são oriundas da madeira, chegam a valores de no máximo 1\%, sendo as cinzas dos eucaliptos da ordem de no máximo 0,28\% (TRUGILHO, 2015). Para esta espécie, portanto, teores acima deste valor dividido pelo rendimento gravimétrico (exemplo: para $R G=35 \%$, teor de cinzas máximo $=0,80 \%$ ) indicam contaminação do CV. Na Carboval, o resfriamento do CV acontece em ambiente protegido de contaminações do solo (Figura 2). Assim, ao contrário do sistema de carbonização artesanal, em que as análises de rotina indicam valores próximos a $4 \%$ de cinzas, no forno de carbonização contínua Carboval esses valores ficam abaixo de 1\%, devido ao Sistema Integrado Carboval não permitir a contaminação com terra nem da madeira e nem do CV produzido: produz-se um 
biocombustível sólido limpo (carvão vegetal) e disponibiliza-se outro biocombustível volátil (gases de carbonização e alcatrão) também limpo e homogêneo.

Toda a energia fornecida ao Reator Carboval é proveniente da energia química contida na madeira. O balanço de energia mostrado na Figura 5, por tonelada de madeira seca como referência $(4400 \mathrm{kcal} / \mathrm{kg}$ de poder calorífico inferior) típico do processo Carboval para um CV com $74 \%$ de carbono fixo.

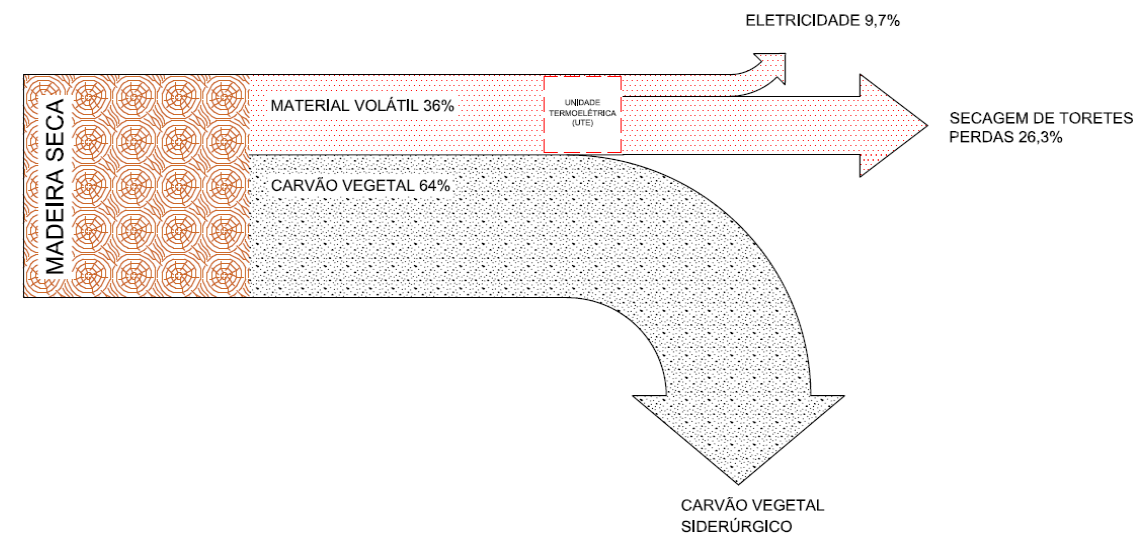

Figura 5 - Balanço de energia típico para o Processo Carboval com 74\% de carbono fixo.

No processo de carbonização contínua Carboval, todos os gases de carbonização gerados estão concentrados e coletados em um único ponto da torre. Esses gases são direcionados para o queimador para fornecimento de parte da energia no processo. Existe a possibilidade, já testada durante o projeto Carboval, do consumo desses gases em uma Unidade Termoelétrica para produção de energia elétrica (Figura 5). Parte do calor sensível dos gases combustos pode ser utilizado para a secagem da madeira, o que é relevante com a busca das empresas pela redução de custo através do aumento de produtividade e uma tendência de aumento da escala de produção nas unidades. Com o aumento da quantidade de fornos Carboval por unidade, aumenta-se a energia disponível para geração de eletricidade.

Para a mesma produção de carvão (Tabela 2), enquanto os fornos de alvenaria lançam na atmosfera 390 t/dia de gases de carbonização, no reator contínuo Carboval, todo o gás emitido é combusto sendo composto de $\mathrm{N}_{2}, \mathrm{CO}_{2}$ e $\mathrm{H}_{2} \mathrm{O}$. Como a emissão de $\mathrm{CO}_{2}$ de fonte renovável não é considerada gás de efeito estufa, a tecnologia Carboval pode ser considerada um processo $100 \%$ limpo e sustentável do ponto de vista ambiental.

Tabela 2 - Balanço de massa aproximado dos sistemas Contínuo Carboval e de Alvenaria.

\begin{tabular}{ccc} 
& $\begin{array}{c}\text { Reator de Carbonização } \\
\text { Contínua Carboval }\end{array}$ & $\begin{array}{c}\text { Forno de Alvenaria com } \\
\text { 150 t de enfornamento }\end{array}$ \\
\hline $\begin{array}{c}\text { Número de torres Carboval / } \\
\text { Fornos de Alvenaria }\end{array}$ & 10 & 70 \\
Enfornamento, t/dia & 500 & 600 \\
$\begin{array}{c}\text { Rendimento Gravimétrico, \% } \\
\text { Emissão de gases não } \\
\text { combustos à atmosfera, t/dia }\end{array}$ & 42 & 35 \\
$\begin{array}{c}\text { Produção de Carvão, t/dia } \\
\text { * Todos os gases emitidos no processo }\end{array}$ & $0^{*}$ & 390 \\
& 210 & 210 \\
& $\mathrm{CO}_{2}, \mathrm{~N}_{2}$ e $\mathrm{H}_{2} \mathrm{O}$.
\end{tabular}




\section{RESULTADOS E DISCUSSÃO}

\section{MATERIAIS E MÉTODOS}

Ao longo de todo o desenvolvimento do sistema Carboval foram produzidas aproximadamente 32.000 toneladas de carvão vegetal, com a carbonização de madeira das mais variadas características. Nesse período, parâmetros de maior relevância e impacto foram quantificados para validação do projeto e alguns destes serão mostrados a seguir.

\subsection{Qualidade Física do Carvão Vegetal Produzido}

Os dados da análise de tamanho médio que serão apresentados foram avaliados entre janeiro e setembro de 2015, período em que foram carbonizados diversos materiais genéticos. A Figura 6 é a representação esquemática do ponto de coleta (antes do silo de armazenamento). A coleta é feita cortando o fluxo de carvão na correia transportadora. Os valores encontrados para tamanho médio do carvão vegetal neste artigo serão superiores aos encontrados na Usina Siderúrgica antes deste ser consumido. Isto se deve ao fato de amostrarmos na saída do reator. As diversas etapas de manuseio até a Usina Siderúrgica (silos, logística e etc.) reduzem este tamanho.
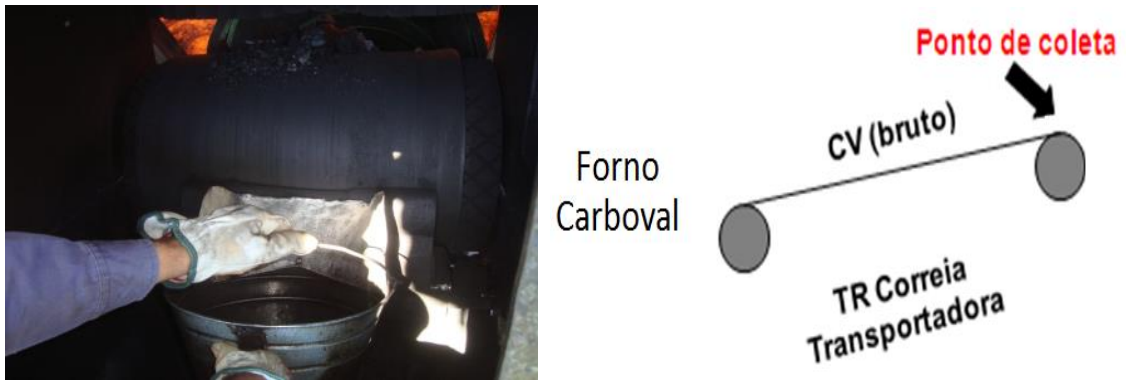

Figura 6 - Amostragem realizada no Sistema Carboval

O procedimento de amostragem é descrito abaixo:

- A cada 4 horas (2 por turno) coletou-se um incremento de amostra de carvão vegetal na correia transportadora como mostrado na Figura 6 , totalizando 6 amostras por dia com um volume de $250 \mathrm{~L}$, durante o desenvolvimento da tecnologia. As análises granulométricas foram realizadas conforme norma ABNT NBR7402 de jul/82.

\subsection{Rendimento Gravimétrico do Reator Carboval}

O rendimento gravimétrico no Forno de Carbonização Contínua Carboval foi monitorado diariamente, por meio de balanças no enfornamento de madeira e na descarga do carvão. Todas essas balanças durante a operação da planta foram calibradas periodicamente e toda madeira enfornada tinha sua umidade conhecida. 


\section{RESULTADOS E DISCUSSÃO}

\subsection{Qualidade Física do Carvão Vegetal Produzido}

Verifica-se no gráfico da Figura 7 , em que as barras correspondem à média de tamanho médio e a barra de erro o desvio padrão, que há uma estabilidade no tamanho médio do carvão produzido pelo forno de Carbonização Contínua Carboval. O tamanho médio inferior durante no mês de julho/2015, se deve ao fato da planta ter carbonizado neste período uma espécie de madeira que resulta em um carvão vegetal de menor tamanho médio.

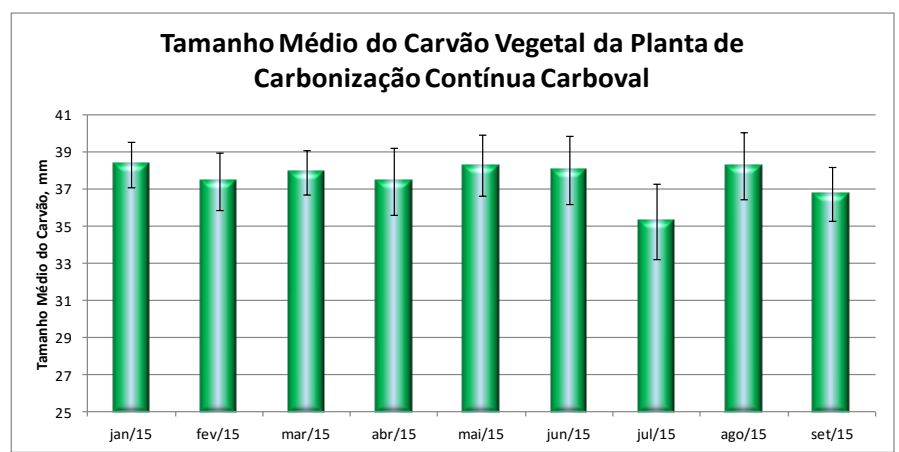

Figura 7 - Tamanho Médio do Carvão Vegetal produzido no Sistema Carboval

\subsection{Rendimento Gravimétrico}

A carbonização, como citado anteriormente é a degradação térmica da madeira, assim, à medida que aumenta a temperatura, há uma perda de massa da biomassa. Para um mesmo processo e qualidade do carvão vegetal produzido, espera-se um mesmo rendimento gravimétrico.

Durante a operação do reator Carboval, o ponto de operação trabalhado em virtude da demanda de qualidade siderúrgica interna, era de 70 a $73 \%$ de carbono fixo, o que implicou em um rendimento gravimétrico variando de 40 a $42 \%$. Estes parâmetros podem ser alterados, bastando para isso uma alteração no ponto de operação (temperatura de carbonização, tempo de residência no reator, e etc.), tanto no sentido de aumento de carbono fixo e queda no rendimento gravimétrico, quanto no sentido contrário.

\section{CONCLUSÕES}

O sistema artesanal atual de produção de carvão vegetal em fornos de alvenaria aproxima-se do seu limite técnico e econômico rapidamente e, para atender as novas exigências ambientais, de custos operacionais e de investimentos adicionais, novas soluções são demandadas.

Os esforços e investimentos ao longo de 8 anos da Vallourec para desenvolver um novo e moderno processo industrial para produção do CV siderúrgico de forma sustentável foram atingidos e sua rentabilidade econômica confirmada considerando a total integração entre floresta e CV Siderúrgico granulado, limpo e homogêneo pronto para embarque sem nenhuma intervenção manual. Foram produzidas $32 \mathrm{mil} \mathrm{t}$ de CV durante os vários testes do reator Carboval. 
Para viabilizar a sustentabilidade desta atividade foi necessário a inserção de tecnologias industriais, carbonização continua, e a integração das atividades de colheita e logística ao processo, tornando o sistema competitivo.

O sistema Carboval de produção sustentável de carvão vegetal siderúrgico desenvolvido pela Vallourec comprovou ser necessário e atraente para a continuidade sustentável das operações de produção de carvão vegetal siderúrgico.

Ao ampliar a escala de produção pelo processo, existem ainda etapas que adicionam valor e elevam a eficiência do sistema integrado Carboval. Trata-se da termogeração, aproveitando todos os resíduos de biomassa da floresta em conjunto com o excesso de energia contida nos gases e bio-óleo produzidos pelo reator durante a carbonização.

\section{REFERÊNCIAS}

1 SAMPAIO, R. S. A Proposed Ecosystem of Manufacture Method to Reduce

Environmental Impact of the Steel Industry. Richard J. Fruehan Symposium: Physical Chemistry of Sustainable Metals - 2011, Carnegie Mellon University, Materials Science and Engineering.

2 FAO - Food and Agriculture Organization of the United Nations. Industrial Charcoal Making. Modern carbonising retort systems, 1985. [acesso em: 02 de abril de 2016]. Disponível em: www.fao.org/docrep/x5555e/x5555e04.htm.

3 ALTHOFF, P. Fields tests of carbon monitoring methods in forestry projects. Forest Carbon Monitoring Program Winrock International Institute for Agricultural Development, 1999, 5-15.

4 TRUGILHO, P. et al. Características de crescimento, composição química, física e estimativa de massa seca de madeira em clones e espécies de Eucalyptus jovens. Ciência Rural, 2015, v.45, n.4, p.661-666. 